information films. N evertheless, the aim is similar: to inform the general public, so that their demand for health care is more focused and appropriate.

\section{Lifetime health record}

The fourth pillar is perhaps the most exciting of all, namely the building of a lifetime health record for each citizen. The envisaged European model includes the issuing of an electronic record to a foetus when the mother's pregnancy is first recognised. This can then become a record of every health care event that the individual experiences over a lifetime. To this accumulating and dynamic dataset can be added genetic information, the individual's changing socioeconomic status throughout life, environmental data such as ambient temperature and pollution levels, as well as information on lifestyles.

There are, of course, major obstacles to the implementation of the lifetime health record, notably the ethical implications of such centralisation of personal data. These will need to be fully debated and controversies regarding civil rights and privacy resolved.

\section{The European future}

The challenge ahead is enormous, but eventually, once the process has started to gather momentum, the benefits for the European patient community are likely to be massive. For example, the duplication of resources that currently exists, with each member state having a pyramidal structure of health care delivery, could be rationalised.

There is an urgent need to move the health care exchange point outside the existing infrastructures (i.e. hospitals and clinics) and, where possible, to make services available within the community. If consultation by electronic media, rather than face to face, were to be widely implemented, we could look forward to a time when diagnostic assessments are carried out in the retail environment or in people's homes, where they spend most of their time, and not in hospitals or clinics. For those vulnerable citizens who have chronic diseases, and especially those who are unable or unwilling to attend hospital for follow-up appointments, it will be possible to conduct many diagnostic tests in the home. W ith the increasing number of elderly citizens in our community, there will be a need for 'sentinel' devices in homes, which will support their independence and provide a safe environment for them. Such devices could be especially relevant to those with dementing illnesses. Some countries in Europe have already begun this process. In the UK, the national programme for health care reform is under way, with a massive increase in investment by the government in the $\mathrm{N}$ ational $\mathrm{H}$ ealth Service (N HS) over the next 8-10 years. Much of the early spending will be on strengthening the information technology component of the N HS, thus making the changes alluded to above possible.

$N$ ot least of the challenges will be the need to accommodate the very disparate health care provision and outcomes in those countries that will be joining the European Community over the next few years. The health care needs of their citizens must be taken into consideration, as, when these countries become full members of the Community, they will have the right to receive health care services matching those received by citizens of the other member states. The time for pilot studies in telemedicine and eH ealth is long past. W hat is necessary now is the large-scale and widespread implementation of eH ealth programmes that will enable European citizens to benefit from quality health care services with equity across the European Community as a whole.

\section{This article is}

based on a book chapter published in Telepsychiatry and e-Mental Health (eds R. Wootton,

P. Yellowlees \&

P. McLaren). London: Royal Society of Medicine (2003). Professor Yellowlees is a director of HealthShare.

\title{
Broadband telecommunications: the bricks and mortar of future eM ental health systems
}

\section{Peter Yellowlees}

Professor of Psychiatry, Centre for Online Health, Level 3, GP South Building (78), Staff House Road, University of Queensland, St Lucia 4072, Australia, email P.Yellowlees@uq.edu.au

ealth care will undoubtedly change over the next 20 or 30 years as eH ealth technologies become increasingly used and accepted (Treister, 1997; Yellowlees, 1997, 2001). At a global level, the health care system is moving away from episodic care to concentrating on continuity of care, especially for patients with chronic diseases (Yack, 2000), who will give rise to the greatest disease burden in the future (Murray \& Lopez, 1999). Many countries are gradually moving away from a focus on the service provider to a focus on the informed patient, and from an individual approach to treatment to a team approach. Increasingly there is a concern less with the treatment of illness and more with the need for wellness promotion and illness prevention, which, of course, parallels a shift away from traditional care to community care.

This is the model of the 'information age health care' described by Ferguson (1994). To move to this future, there needs to be a strengthening of the availability and use 
of information to facilitate changes in health service delivery (Smith, 1997). The requisite technologies should have four main objectives:

o to empower consumers and clinicians in day-to-day health care delivery by improving access to evidencebased information at the point of care

0 to facilitate the delivery of a wider range of services within primary and community care

0 to provide accurate data to support research, clinical policy and governance arrangements

0 to ensure that there is a sustainable, secure and reliable electronic environment, which, of course, must be underpinned by strong, policy-driven privacy protection.

All of the potential barriers to the adoption of eH ealth are gradually being overcome. Prices have come down, technology has become more user-friendly, especially software, and doctors themselves have gradually started to become convinced of the usefulness of eH ealth programmes. The single most important change, however, is the increasing availability of broadband access, which allows the development of so phisticated video-based applications, particularly on the doctor's desk. The increase in the availability of broadband systems, whether these be satellitebased, cable, fibre or digital subscriber lines (DSL), means that, with their reduced prices, there is simply more opportunity to provide effective eH ealth services.

\section{Health care networks of the future}

W hatever technological changes occur, the major challenge will be to make new technology available at the point of care with the patient. Here is where the use of broadband networks, such as internet2 (www.internet2.edu), is crucial. As health care is increasingly undertaken on the internet, some of the business models relevant to the distributed environment of the internet will become important in mental health. The traditional doctor-patient relationship is mirrored by the business-to-consumer (B2C) relationship. The B2C market will continue to amalgamate and expand, based on the core doctor-patient relationship but with fewer boundaries and more potentially difficult ethical contradictions and problems, especially for the doctors, including psychiatrists, involved.

The business-to-business (B2B), or doctor-doctor or health system- health system market, is probably even larger. At a clinical level, eM ental health will allow psychiatrists to consult via the primary care doctor's desktop, using video technology. This will allow primary care doctors to seek rapid referrals and assessments from specialists, yet to maintain their relationship with their patient and not duplicate tests that might otherw ise be performed by both themselves and the specialist to whom a patient is referred. Increasingly, this liaison style of consultation, where the specialist both sees the patient and teaches the primary care provider, will become routine; in many instances the patient will not necessarily be present, as the primary care practitioner is essentially supervised by the specialist.

This approach could lead to major changes in how health care is organised and delivered. Psychiatrists in, for

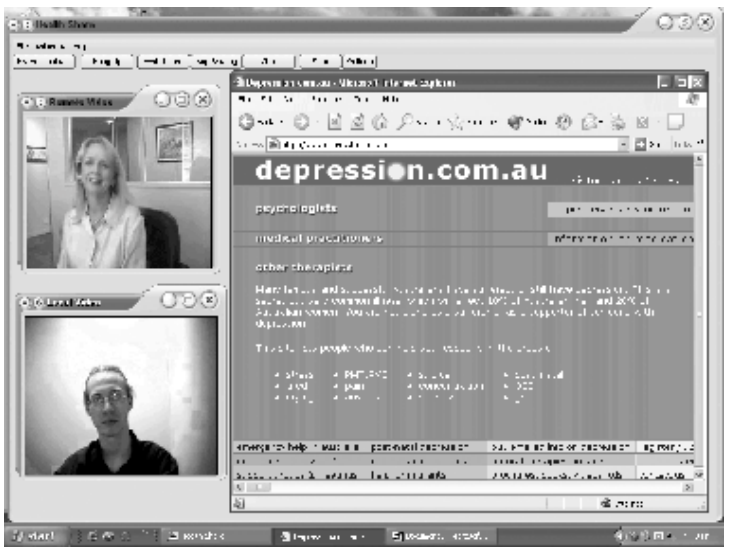

Fig. 1. The HealthShare portal, demonstrating an online health service environment in use in Australia.

instance, Sydney might supervise practitioners and their patients in $\mathrm{N}$ ew York because the international exchange rates make that financially acceptable, whereas practitioners in Boston might consult to Saudi Arabia, perhaps because of a particular individual expertise that makes up for the added cost. It is likely that, in the near future, global health care portals using broadband internet-based systems such as that developed by HeatthShare (www.healthshare.com.au) (see Fig. 1), an Australian company, will be common.

\section{Global clinicians of the future}

It is inevitable that, over time, we will move to global health care systems, with psychiatrists and patients interacting in electronically distributed environments around the world, supported by broadband technologies, either wired or wireless. These global delivery environments on the doctor's desktop or in the patient's home will incorporate a variety of features, including video technology to allow video consultations in real time, or video email for storeand-forward programmes, as well as electronic consumerowned or provider-shared, voice-driven health records. On the doctor's desktop there will be appropriate practice management and communications so ftw are that will be serviced from central servers or that may be kept on the doctor's own local network to allow him/her to link seamlessly in a peer-to-peer relationship with colleagues. This same desktop will have a very strong educational focus, as psychiatrists and other health care professionals will be able to receive their continuing health education, for professional credits and re-accreditation needs, via their desktop. They could achieve this by taking part in interactive videoconferences and virtual conferences on the internet, given by experts in their field and relayed to, potentially, many thousands of different sites; in addition, they could achieve this in a large number of flexible, work-based teaching environments, using video, audio and text, which will allow interactive quizzes simultaneously to be taken and marked and to be recorded for long-term monitoring.

The roles of some psychiatrists will change: many, for instance, will increasingly focus on the teaching and supervision of other health professionals and of groups of
It is inevitable

that, over time, we will move to

global health care systems, with

psychiatrists and patients interacting in electronically distributed

environments around the world,

supported by broadband technologies. 
consumers. Some specialists who are particularly good teachers will probably gradually migrate into the role of 'world authority' in certain areas. This is already happening in commercial university programmes, where some individual professors, mainly in areas such as business and economics and from universities like Yale and Harvard, have already become educational 'superstars'. Students will now enrol as much to hear their lectures as to take a particular course, and teachers will increasingly be employed to 'headline' particular teaching programmes, to attract students. There is a parallel here with how sports teams buy individuals with special talents to ensure success both on the field and financially. There is absolutely no reason why future university programmes will not head in the same direction as our current sports teams, and this will be supported by the eH ealth environments of the future, which will allow such 'superstar' teachers, many of whom will come from the health world, to be fitted easily into prearranged courses and programmes, anytime, anywhere. Health education programmes will become more flexible and will be available ubiquitously.

\section{A future distributed eHealth care environment}

All of this will require a focus on distributed or enterprise systems of information and communications techno logy, and countries around the world are now beginning to address the variety of technical issues involved.

The health system has to meet the challenges contained in the recent crucially important report from the Committee on Q uality Healthcare in America, published by the Institute of Medicine (Ross et al, 2001). This influential report notes that 'information technology must play a central role in the redesign of the healthcare system' and suggests that the U nited States needs a renewed national commitment to build an information infrastructure to support health care delivery, and that 'commitment should lead to the elimination of most handwritten clinical data by the end of the decade'. For that to happen, the health system has to think seriously about its basic infrastructure requirements, and in the next century these will increasingly involve close collaboration with telecommunications providers.

\section{References}

Ferguson, T. (1994) From industrial age medicine to information age health care. In The Millennium Whole Earth Catalog (ed. H. Rheingold). San Francisco, CA: Harper.

Murray, C. J. \& Lopez, A. (1999) On the comparable quantification of health risks: lessons from the Global Burden of Disease Study. Epidemiology, 10, 594-605.

Ross, M. D., Twombly, I. A., Bruyns, C., et al (2001) Crossing the Quality Chasm. A N ew Health System for the Twenty-First Century. Albuquerque, N M: Institute of Medicine, University of $\mathrm{N}$ ew Mexico Health Sciences Center.

Smith, R. (1997) The future of healthcare systems. British Medical Journal, 314, 1495-1497.

Treister, N. W. (1997) Marketing and the medical specialist in the managed care environment. Physician Executive, 23(6), 1419.

Yack, D. (2000) Chronic disease and disability of the underprivileged: tackling challenges. Business Briefing: Global Health Care, 0 ctober, 45-49.

Yellowlees, P. (1997) Successful development of telemedicine systems - seven core principles. Journal of Telemedicine and Telecare, 3, 215-222.

Yellowlees, P. (2001) Your Guide to eH ealth - Third Millennium M edicine on the Internet. Brisbane: U niversity of Q ueensland Press.

\title{
Cost issues with telepsychiatry in the United States
}

\author{
Donald M. Hilty리 James A. Bourgeois ${ }^{2}$, Thomas S. Nesbitt ${ }^{3}$ \\ and Robert E. Hales ${ }^{4}$
}

\begin{abstract}
${ }^{1}$ Associate Professor of Clinical Psychiatry and Behavioral Sciences, Director of Telepsychiatry, University of California Davis Medical Center, 2230 Stockton Boulevard, Sacramento, CA 95817, USA, email dmhilty@ucdavis.edu

${ }^{2}$ Associate Professor of Clinical Psychiatry and Behavioral Sciences, Chief, Consultation-Liaison Division, University of California Davis Medical Center, Sacramento, California, USA

${ }^{3}$ Associate Professor of Family and Community Medicine, Associate Dean, Regional Outreach and Telehealth, University of California Davis Medical Center, Sacramento, California, USA

${ }^{4}$ J oe P. Tupin Professor and Chair of Psychiatry and Behavioral Sciences, University of California Davis Medical Center, Sacramento, California, USA
\end{abstract}

ideoconferencing has increased patient access
to psychiatric care by linking specialists at
academic or regional health centres with primary
health care professionals in shortage areas (Hilty
et al, 1999, 2002). Preliminary studies have demonstrated positive outcomes and user satisfaction (H ilty et al, 2002). Information is still being sought regarding costs because of a paucity of clinical outcome studies, cost data and randomised trials. 